Supplement of Geosci. Model Dev., 12, 2155-2179, 2019

https://doi.org/10.5194/gmd-12-2155-2019-supplement

(c) Author(s) 2019. This work is distributed under

the Creative Commons Attribution 4.0 License.

(c) (1)

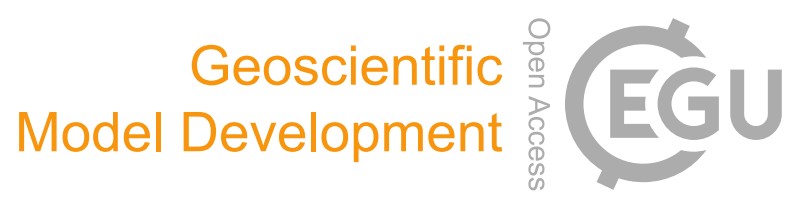

Supplement of

\title{
The Monash Simple Climate Model experiments (MSCM-DB v1.0): an interactive database of mean climate, climate change, and scenario simu- lations
}

Dietmar Dommenget et al.

Correspondence to: Dietmar Dommenget (dietmar.dommenget@monash.edu)

The copyright of individual parts of the supplement might differ from the CC BY 4.0 License. 


\section{Supplementary Figure 1}

(A) $[3 x] \mathrm{loo} /$ Snow [0 C]

Entire Grid Undefined
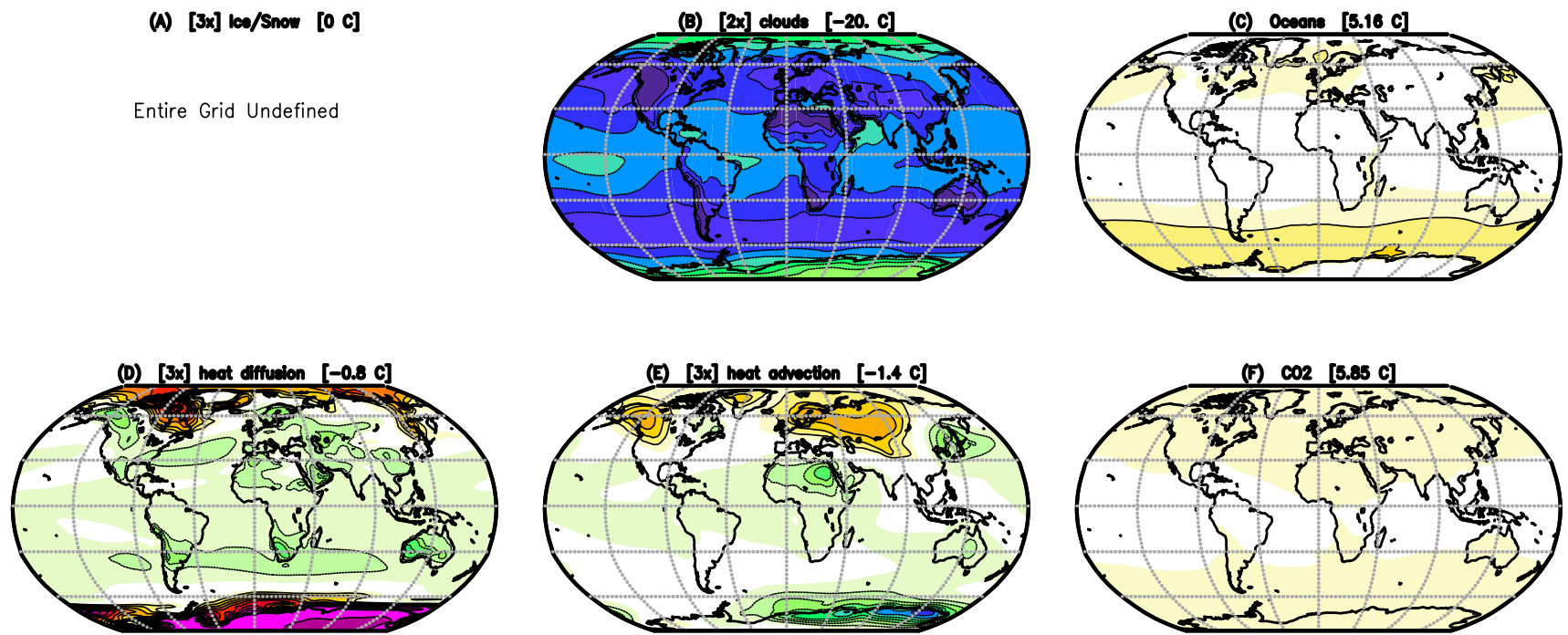

(Q) Hydrolopiod oyclo [23.2 c]
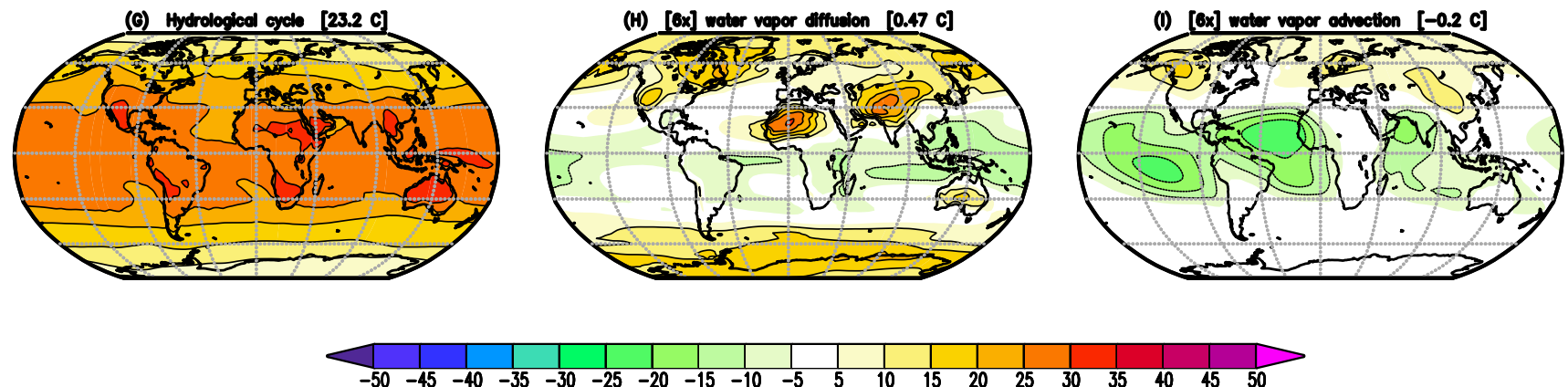

Figure 1: Changes in the annual mean $T_{\text {surf }}$ in the GREB model simulations with different processes turn OFF as in Fig. 5 but relative to the complete GREB model without model correction terms and without Ice/Snow: (a) undefined, (b) clouds, (c) oceans, (d) heat advection, (e) heat diffusion, (f) $\mathrm{CO}_{2}$ concentration, (g) hydrological cycle, (h) diffusion of water vapour and (i) advection of water vapour. Global mean differences are shown in the headings. All values are in ${ }^{\circ} \mathrm{C}$. In some panels, the values are scaled for better comparison: (a), (d) and (e) by a factor of 2 , and (h) and (i) by a factor of 5 . 


\section{Supplementary Figure 2}
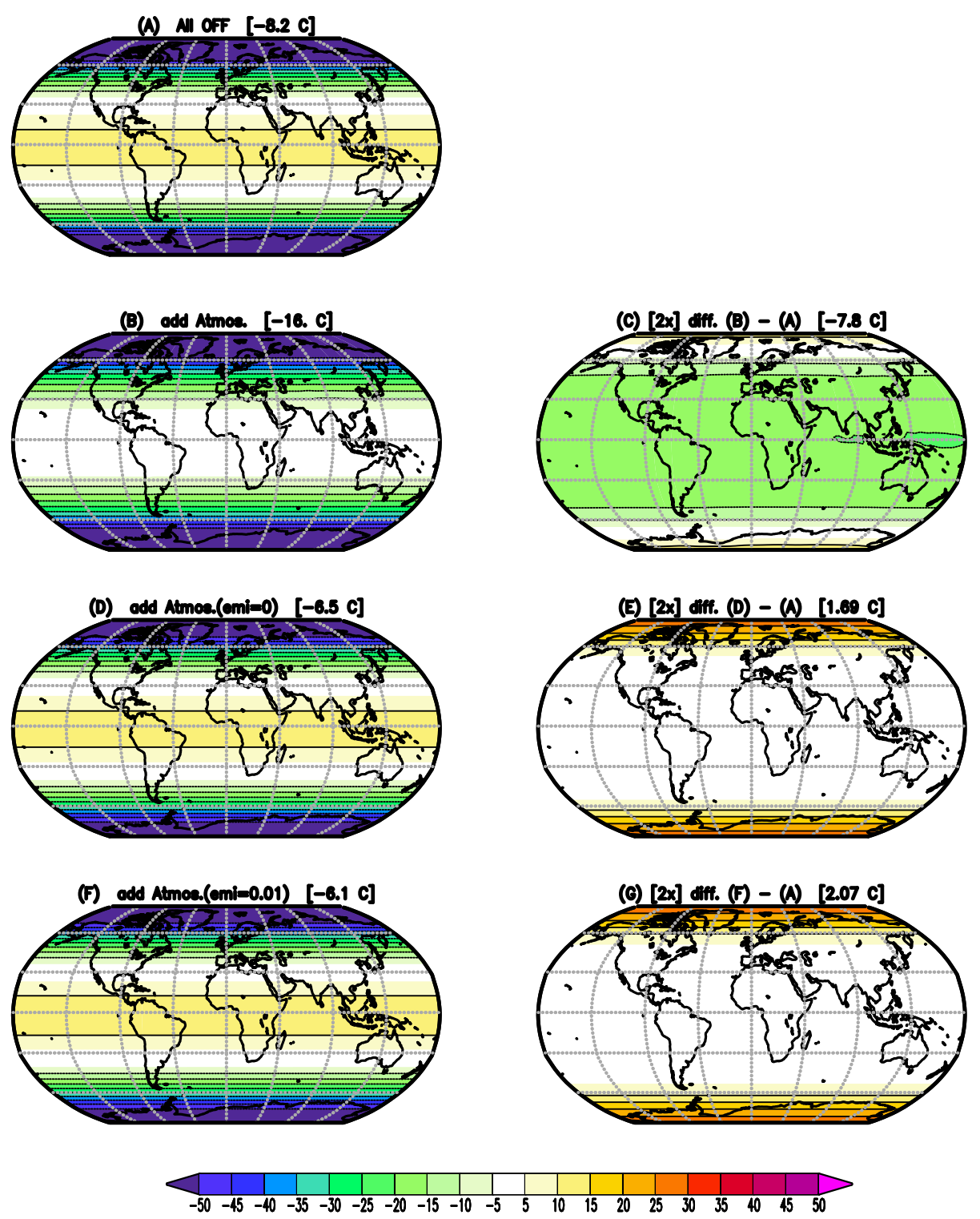

Figure 2: Conceptual build-up of the annual mean climate as in Fig. 8. Panels (a) to (c) as in Fig. 8. (d) with the atmospheric emissivity set to zero, and (f) with the emissivity set 0.01. The panels on the right column show the difference of the left panel to (a). Global mean values are shown in the heading. All values are in ${ }^{\circ} C$. In the right column, the values are scaled by a factor of 2 for better comparison. For details see on the experiments see Section $2 \mathrm{a}$. 